Case report

\title{
Pediatric glioblastoma treated with concurrent radiotherapy and adjuvant Temozolomide: A case study of the treatment of pediatric GBM by the technique of volumetric modulated arc therapy
}

\section{Pedijatrijski glioblastom liječen istodobnom radioterapijom i adjuvantnim Temozolomidom: Studija slučaja liječenja pedijatrijskog GBM-a tehnikom volumetrijski modulirane lučne terapije}

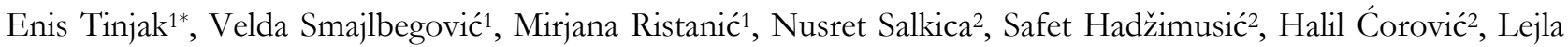
Altumbabić ${ }^{3}$

\footnotetext{
${ }^{1}$ Oncology clinic, Clinical Center of Sarajevo University, Sarajevo, Bosnia and Herzegovina

${ }^{2}$ Clinic for Nuclear Medicine and Endocrinology, Clinical Center of Sarajevo University, Sarajevo, Bosnia and Herzegovina

${ }^{3}$ Clinic for anesthesia and resuscitation, Clinical Center of Sarajevo University, Sarajevo Bosnia and Herzegovina Coresponding author: Enis Tinjak, Oncology clinic, Clinical Center of Sarajevo University, Bolnička 25, 71000 Sarajevo, Bosnia and Herzegovina , email: t-enis@hotmail.com
}

Received:09.09.2021.

Accepted:20.10.2021.

DOI: https://doi.org/10.48026/issn.26373297.2021.12.1.4

\begin{abstract}
Introduction: Glioblastoma in children (pGBM) occurs somewhat less frequently than in adults. Pediatric pGBMs have a different molecular profile than GBM for adults. The aim of the presentation of this case is the possibility of the effectiveness of the GBM radiation method and the evaluation of magnetic resonance imaging, and the monitoring of the treatment outcome of the patient.

Material and methods: The case study is of the retrospective-prospective type. Medical documentation, magnetic resonance imaging, and chronologically monitored evaluation of the findings from November 2018 to August 2021 were used to present the study. The postoperative course was analyzed, as well as the effect of concurrent chemoradiotherapy, VMAT radiotherapy and adjuvant chemotherapy with Temozolomide in a patient aged 4 years and 6 months, comparing treatment outcome with median and overall survival in glioblastoma.

Results: The pediatric patient after being diagnosed with high-grade glioma in 2018 is so far in very good general condition, without signs of physical and psycho-social defects, which compared to the scientifically proven median of survival indicates a good therapeutic effect. Volumetrically modulated arc radiotherapy with the use of modern IGRT verification techniques and with the use of chemotherapy with Temozoloimod, has proven to be a still effective oncological method treatment of GBM. For the final outcome of the disease and the effect of therapeutic modalities, the patient's condition and evaluation of magnetic resonance imaging will be monitored. The result supports further research into this therapeutic regimen.

Conclusion: Glioblastoma is a very aggressive tumor, which occurs somewhat less frequently in the pediatric population than in adults, but is a very fatal disease. Surgical resection followed by concurrent chemoradiotherapy, with adjuvant Temozolomide is still the method of choice in the treatment of glioblastoma.
\end{abstract}

Keywords: Radiotherapy, pediatric glioblastoma (pGBM), Temozolomide. 
Apstrakt

Uvod: Glioblastom kod djece (pGBM) javlja se nešto rjeđe u odnosu na odrasle. Pedijatrijski pGBM ima različit molekularni profil u odnosu na GBM za odrasle. Cilj prikaza ovoga slučaja jeste mogućnost učinkovitosti metode zračenja GBM-a i evaluacija imidžinga magnetnom rezonansom, te praćenje ishoda liječenja bolesti.

Materijal i metode: Studija slučaja je retrospektivno-prospektivnog tipa. Za prikaz studije korištena je medicinska dokumentacija, snimci magnetne rezonance, hronološki praćena evaluacija nalaza od novembra 2018. godine do avgusta 2021. godine. Analiziran je postoperativni tok, kao i učinak istodobne kemoradioterapije, tehnikom radioterapije VMAT i adjuvantne kemoterapije Temozolomidom na pacijentu dobi od 4 godine i 6 mjeseci, upoređujući ishod liječenja sa medijanom i ukupnim preživljenjem kod glioblastoma.

Rezultati: Pacijent pedijatrijske populacije, nakon dijagnosticiranja glioma visokog stupnja 2018. godine, do sada u veoma dobrom općem stanju, bez znakova fizičkih i psiho-socijalnih nedostataka, što u usporedbi sa naučno dokazanim medijanom preživljenja upućuje na dobar terapijski učinak. Volumetrijski modulirana lučna radioterapija uz primjenu savremenih IGRT tehnika verifikacije, te uz primjenu kemoterapije Temozolomidom, pokazala se kao još uvijek učinkovitom onkološkom metodom liječenja GBM-a. Za konačan ishod bolesti i učinka terapijskih modaliteta, pratit će se stanje pacijenta i evaluacija snimaka magnetnom rezonancom. Rezultat podupire daljnje istraživanje ovoga terapijskog režima.

Zaključak: Glioblastom je veoma agresivan tumor, koji se u pedijatrijskoj populaciji javlja nešto rjeđe u odnosu na odrasle, ali je veoma pogubna bolest. Hirurška resekcija praćena istodobnom kemoradioterapijom, sa adjuvantnim Temozolomidom još uvijek je metoda izbora kod liječenja glioblastoma.

Ključne riječi: Radioterapija glioblastoma, pedijatrijski glioblastom pGBM, Temozolomid.

\section{Uvod}

Glioblastom u djece (pGBM) u usporedbi s odraslima, relativno je rijedak. Glioblastom (GBM) ne čini više od 3-15\% (prosječno od 5-10\%) primarnih tumora centralnog nervnog sistema (CNS) u djece. To je unatoč činjenici da su tumori CNS-a najčešći solidni tumori u djetinjstvu, a 40-50\% ovih tumora čine astrocitomi. GBM ostaje jednako pogubna bolest kod djece sa značajnim morbiditetom i mortalitetom. Dosadašnji izvještaji ukazuju da se medijan preživljenja u pGBM kreće od 13 do 73 mjeseca s petogodišnjim preživljavanjem manjim od 20\%. Najveća incidencija pGBM-a je u dobi od 15 do 19 godina (1).

Gliomi visokog stupnja (HGG) najmanje su 20 puta češći u odraslih nego u djece, osobito GBM. Trenutna klinička praksa liječenja dječijih glioma visokog stupnja uključuje hiruršku resekciju nakon koje slijedi terapija zračenjem (djeca u dobi od 3 godine) uz istodobnu i adjuvantnu kemoterapiju $\mathrm{s}$ Temozolomidom. Trenutno su dječiji HGG (pHGG) vodeći uzrok smrtnosti od raka u djetinjstvu, a razlog više je nepostojanje potpuno učinkovite terapije (2).

\section{Studija slučaja}

Muško dijete u dobi od 4 godine i 6 mjeseci pokazuje simptome povraćanja, glavobolje, vrućice, pospanosti, opće slabosti, epileptičnog napada absans tip. Nakon hospitalizacije na Pedijatrijskoj Klinici, Kliničkog centra Univerziteta u Sarajevu (KCUS), liječen je antibiotskom i simptomatskom terapijom, te su učinjene dodatne dijagnostičke pretrage. U razdoblju od novembra do decembra 2018. godine, dijete je hospitalizirano na Neurohirurškoj klinici KCUS zbog operativnog zahvata ekspanzivnog procesa hipotalamusa i hidrocephalus internus consecutivus koji je radiološki verificiran.

MRI mozga u novembru 2018. godine pokazuje opsežnu zonu promijenjenog intenziteta signala $u$ hipotalamičkoj regiji na sagitalnim snimcima promjera 39x39 mm i kraniokaudalno promjera 49 $\mathrm{mm}$. Opisana promjena je kompresivna na akvadukt i djelomično na III moždanu komoru s izraženom dilatacijom lateralnih moždanih komora, IV moždana komora je također blago dilatirana. Opisana promjena odgovara tumoru iz skupine glioma - gliom visokog stupnja. 


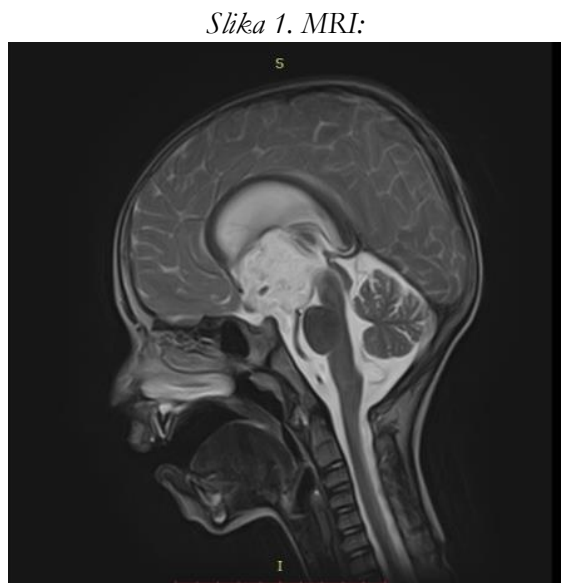

a) $T 2 W$ sagital

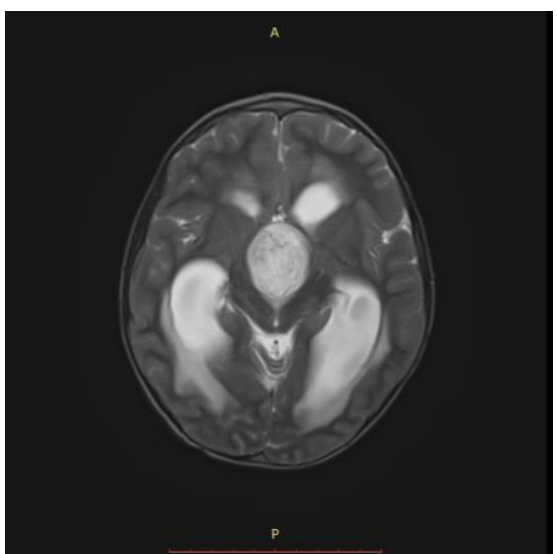

b) T2WI axial

Prvi hirurški zahvat izveden je u novembru 2018. godine, kada je urađena kraniotomija frontoparietalis dexter. Resekcija tumora subtotalis transcallosus transventricularis transforaminalis bilateral.

$\mathrm{Na}$ temelju lokalnog nalaza (potkožno prikupljanje cerebrospinalne tekućine na mjestu operacije) i nalaza CT-a koji upućuju na hidrocefalus, indiciran još jedan operativni zahvat koji je obavljen u decembru 2018. godine, te se postavlja ventrikuloperitonealni šant.

Dijagnoza: Tm hipotalamus. Hydrocephalus internus consecutivus. Fenestratio septi pelucidi, ventriculoperitoneostomia lateral dexter.

$\mathrm{Na}$ postoperativnom kontrolnom pregledu dijete $\mathrm{u}$ dobi od 4 godine i 6 mjeseci, svjesno, orijentirano, komunikativno, odgovara na pitanja, samostalno mobilno, bez neurološkog deficita i lateralizacije. Lokalno na koži glave vidljiv postoperativni ožiljak, uredno zarastao uz manju krustoznu promjenu u sanaciji.

Patohistološki nalaz pokazuje sljedeće rezultate: Zbog svog položaja i morfološkog izgleda (veličina tumora 25x10x5 mm), uključuje dijagnozu difuznog glijalnog tumora srednje linije. Imunohistohemijski tumor pozitivan na GFAP, negativan na IDH1 (wild type), ne zadržava bojenje na ATRX, negativan je na p53. Potrebno uraditi H3K27 i H3K27me. Revizija nalaza PHD: negativan na IDH1, ATRX, pozitivan na $\mathrm{p} 53$ s proliferacijom Ki67 prisutnom u približno $25 \%$. H3K27 negativan (wild type). S obzirom na ovaj profil, nalaz završava kao glioblastom multiformni stupanj IV.

Dijete je predstavljeno na neurohirurškoonkološkom konziliju u decembru 2018. godine, kada se uvidom u medicinsku dokumentaciju, uz konsultacije $i$ nadzor pedijatrijskog onkologa, ukazuje na istovremenu kemoterapiju $s$ Temozolomidom (TMZ) i radioterapiju. Roditelji daju svoj pisani pristanak za onkološko liječenje.

U razdoblju od januara do februara 2019. proveden je radikalni radioterapijski tretman na područje mozga, hipotalamusa i ležište primarnog tumora.

Simulacija i tretman radioterapije proveden je uz obveznu anesteziološku potporu radi sigurnije fiksacije i imobilizacije pacijenta tokom liječenja. Planiranje radioterapijskog tretmana izvršeno je na osnovu fuzije snimaka planiranog CT-a i dijagnostičkih MRI snimaka, kako bi se definirali ciljni volumeni i normalne zdrave anatomske strukture.

Radioterapijski tretman planiran je na sistemu za planiranje (TPS) Eclipse v. 15.5, (Varian Medical Systems, Palo Alto, SAD). Liječenje je provedeno tehnikom radioterapije Rapid Arc na linearnom akceleratoru TrueBeam v.2.7 (Varian Medical Systems, Palo Alto, SAD) i energijom zračenja od 6 MV. Pretretmanska slikovna verifikacija, radioterapija vođena slikom (IGRT) izvedena je pomoću KV pair i CBCT modaliteta snimanja. Propisana tumorska doza (TD) isporučena na mozak, područje hipotalamusa bila je 50,4 Gy kroz 28 frakcija sa 1,8 Gy dnevno, te dodatak (boost) na samo ležište tumora u dozi od 7,2 Gy kroz 4 frakcije. Kemoterapija sa Temozolomidom primjenjena je prema terapijskom protokolu u dozi od $55 \mathrm{mg} / \mathrm{m}^{2}$ $\left(75 \mathrm{mg} / \mathrm{m}^{2}\right)$ dnevno koju je preporučio dječiji onkolog, istovremeno sa radioterapijom u trajanju od 42 dana. Laboratorijski nalazi kontrolirani su sedmično (KKS, DKS, AST, ALT, LDH). Liječenje proteklo bez poteškoća i sa zadovoljavajućim općim stanjem djeteta.

Adjuvantni monoterapijski tretman Temozolomidom započeo je u martu 2019. godine, 28 dana nakon završetka konkomitantne kemoradioterapije. Pacijent je imao ukupno 6 ciklusa 
kemoterapije, terapija je primjenjena prema protokolu doziranja. Kroz prvi ciklus isporučena je doza od $112 \mathrm{mg} / \mathrm{m}^{2}\left(150 \mathrm{mg} / \mathrm{m}^{2}\right)$, drugi ciklus 150 $\mathrm{mg} / \mathrm{m}^{2}\left(200 \mathrm{mg} / \mathrm{m}^{2}\right)$, a kasnije $150 \mathrm{mg} / \mathrm{m}^{2} \mathrm{u}$ kapsulama. Između svakog ciklusa je slijedila pauza od 23 dana. Kontrola laboratorijskih nalaza vršena je sedmično. Monoterapija Temozolomidom završava u avgustu 2019. godine.

Prvi kontrolni pregled MRI glave proveden je u martu 2019. godine, 4 sedmice nakon završetka radioterapijskog liječenja. Dijete je u dobrom općem stanju, negira tegobe i nema neuroloških ispada.

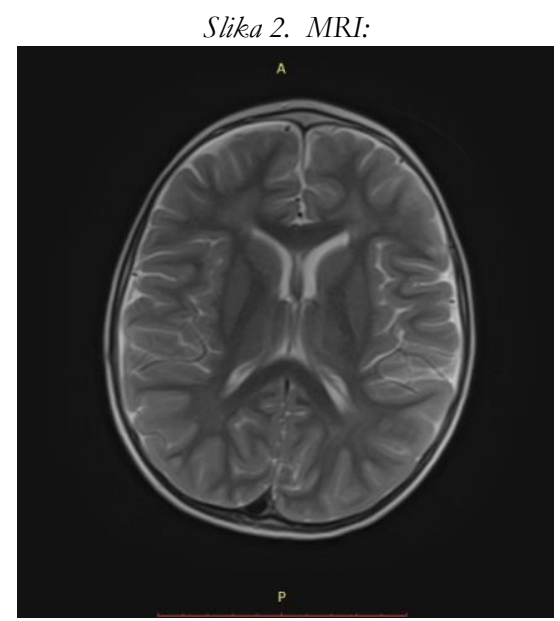

a) T2 WI axial

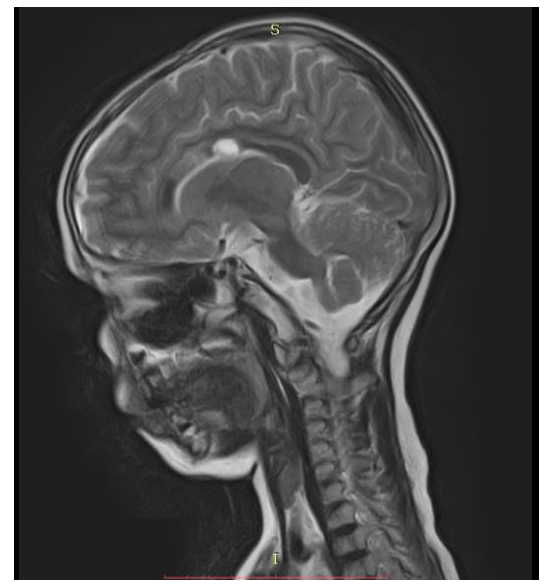

b) T2 WI sagital

Kontrolni nalaz MRI mozga urađenog u maju 2019. godine ukazuje na blagu progresiju u području hipotalamusa, čiji je opseg nešto veći (mjeri 18x24x38 mm), u usporedbi s prethodnim nalazom MRI iz marta 2019. godine (mjeri 16x22x33 mm). Opisani rezidum širi se prema ventralno gdje dolazi u bliski kontakt sa stražnjom konturom optičke hijazme, bez kompresije i na pons. Također, širi se prema kranijalno gdje gotovo potpuno ispunjava III moždanu komoru, ali bez utjecaja na širinu bočnih ventrikula.

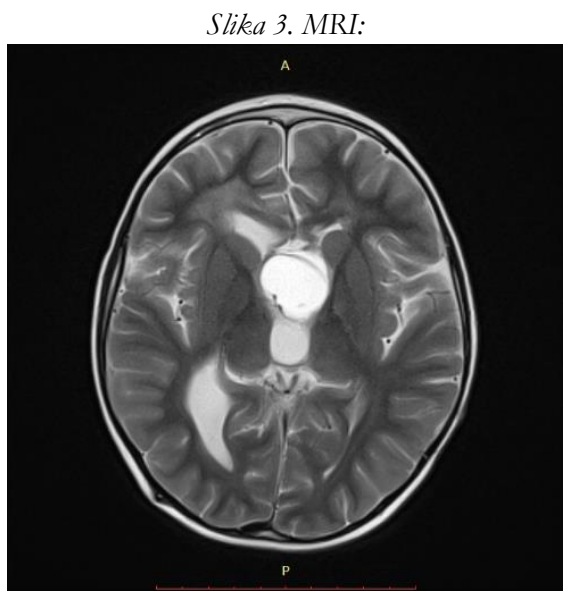

a) T2 blade transversal

b)

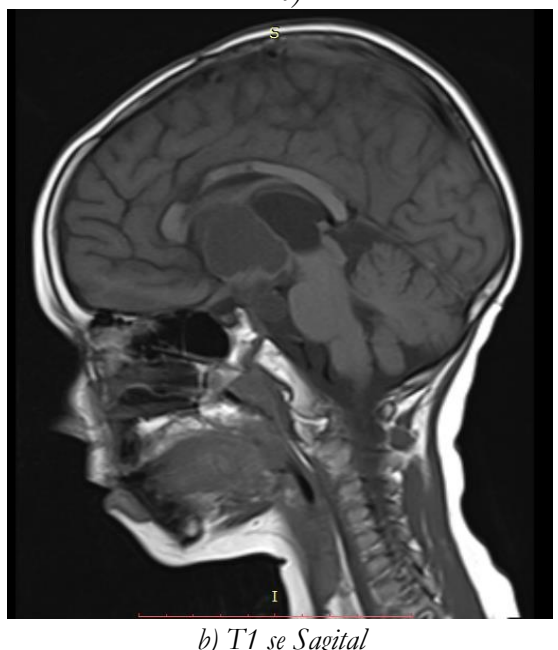

Kontrolni nalaz MRI mozga u septembru 2019. godine, u blagoj je progresiji u usporedbi s ranijim nalazom MRI iz maja 2019. godine. Nalaz ukazuje na progresiju u veličini prethodno verificiranog reziduma na području hipotalamusa, koji prema sadašnjem MRI pregledu mjeri 27x41x45 mm (LLxAPxCC), dok je na prethodnom MRI pregledu mjerio $18 \times 24 \times 38 \mathrm{~mm}$.

U septembru 2019. godine pacijent je ponovo podvrgnut operativnom zahvatu kada se uradi ventriculoperitoneostomia lateral dexter. Postoperativni oporavak protekao je u dobrom općem stanju pacijenta.

MRI mozga u junu 2020. godine ukazuje na stacionarnu osnovnu bolest $u$ usporedbi $s$ prethodnim nalazom MRI-a. Nema znakova endokranijalnog širenja cerebrospinalne tekućine. Ventrikularni sistem ima priližno usporedive dimenzije u odnosu na prethodni nalaz. 


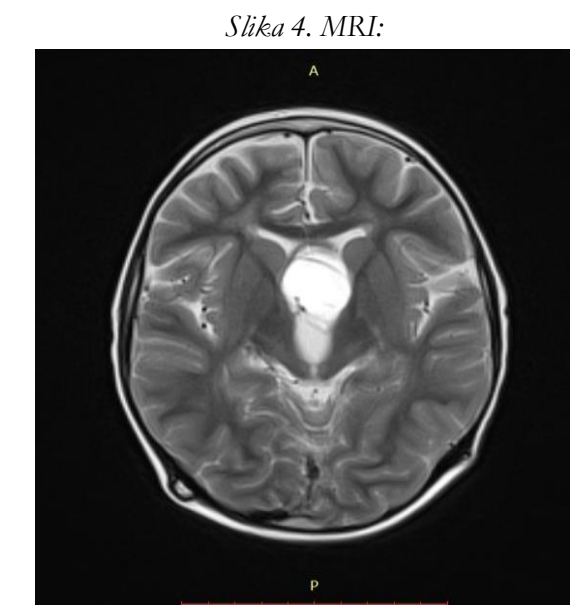

a) T2 blade transversal

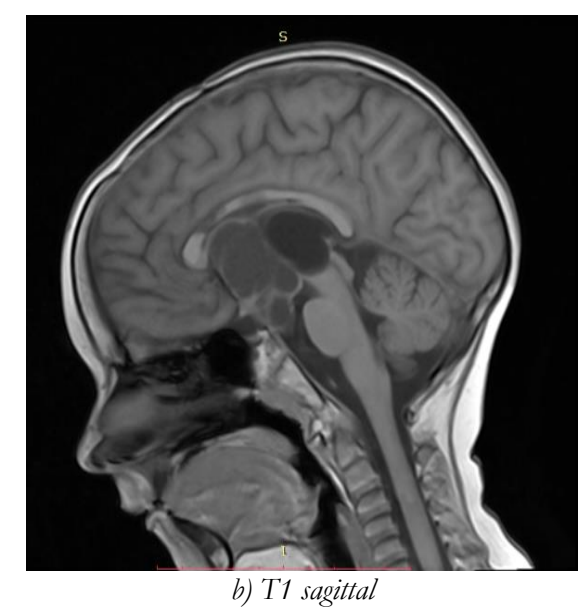

PET / CT nalaz u septembru 2020. godine snimljen od glave do sredine bedra nakon uvođenja $3 \mathrm{mCi}$ 18F-FDG (fluorodeoksiglukoze). Neposredno prije početka, nivo glukoze je $3,3 \mathrm{mmol} / \mathrm{L}$. PET CT je pokazao da nema detektiranih žarišta intenzivnog, jasno patološkog nakupljanja fluorodeoksiglukoze koje bi ukazivale na postojanje tumorskog tkiva FDG-avidnog.

Nalazi biomarkera urađeni su u januaru 2021. godine. Mutacijsko opterećenje tumora krvi - 0 muta/Mb. Nema terapija ili kliničkih ispitivanja. Status mikrosatelita ne može se odrediti. MSI-High nije otkriven. Nema dokaza o genomskoj nestabilnosti. Nisu otkrivene genomske promjene koje se mogu prijaviti. Tumorska frakcija ne može se odrediti.

Kontrolni pregled magnetnom rezonancom proveden je u martu 2021. godine primjenom paramagnetskog kontrastnog sredstva. Dobiveni nalaz u usporedbi s prethodnim iz novembra 2020. godine, pokazuje smanjenje dilatacije desne bočne komore, koja je izmjerena na koronalnim snimcima $\mathrm{u}$ visini foramena Monro širine $21 \mathrm{~mm}$ (prethodni nalaz bio je $28 \mathrm{~mm}$ ).
Slika 5. MRI:

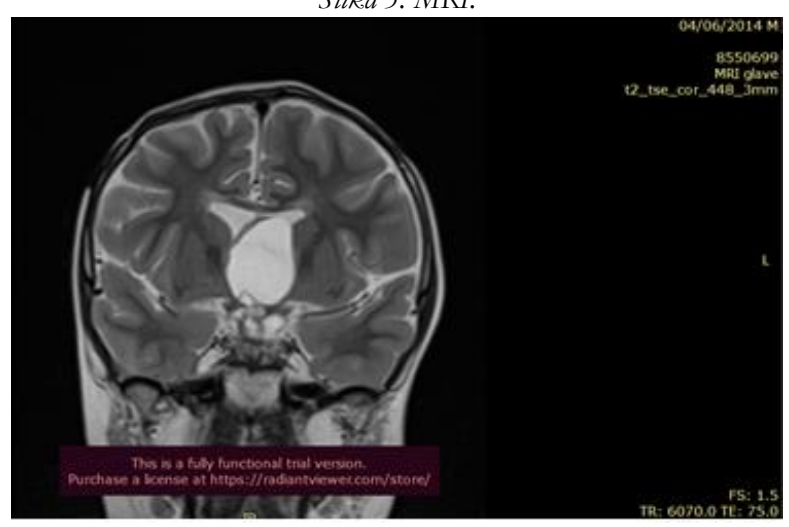

a) T2 tse coronal

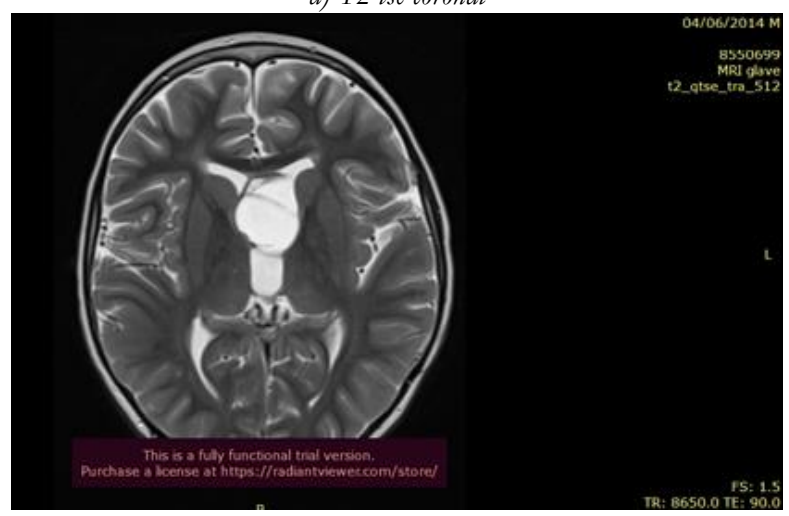

b) T2 qtse traversal

Regresija dilatacije desnog temporalnog roga na fiziološku širinu. Povratak liječene neoplazme ima čvrstu cističnu strukturu, intenzivno kontrastno bojenje čvrstih dijelova i stijenki cistične komponente, u usporedivoj mjeri u poređenju sa prethodnim MR pregledom. Promjeri lezije sada su 31×27x56 mm (bili su 30x30x58 mm, dok je prethodno izmjeren nalaz 30x26x $55 \mathrm{~mm}$ APxLLxCC, mjeren na postkontrastnim tomografijama). Lijeva bočna komora fiziološke širine, druga komora bila je proširena na $15 \mathrm{~mm}$ dok sada iznosi $13 \mathrm{~mm}$. IV komora je uobičajene širine i oblika. Nema znakova širenja cerebrospinalne tekućine. Kontrolni snimci magnetnom rezonancom rađeni su unutar tri mjeseca.

Dijete je sada starosti sedam godina. Pohađa prvi razred osnovne škole. Rekreativno se bavi sportom, komunikativan i bez vidljivih znakova psihosocijalnih nedostataka i poremećaja. 
Diskusija

U studiji Jalali R, et al. pokazuju da je 66 uzastopne djece s histološki dokazanim GBM-om podvrgnuto maksimalno sigurnoj resekciji nakon koje je uslijedila žarišna radioterapija (propisana doza je bila 59,4 Gy u 33 frakcije ili 60 Gy u 30 frakcija) uz istodobni i adjuvantni Temozolomid (doza od $75 \mathrm{mg} / \mathrm{m} 2 /$ dan s profilaktički antiemetik i lijek Pneumocystis carinii). Prosječna stopa preživljavanja bila je 15 mjeseci. Ukupna stopa preživljavanja nakon 1 godine bila je $62 \%$, nakon 2 godine $30 \%$, a nakon 3 godine $27 \%$ (3). Gandhi A, et al. retrospektivno su analizirali 23 pacijenta s pGBM koji su liječeni od 2004. do 2010. Pacijenti su podvrgnuti adjuvantnoj terapiji koja je uključivala konformalnu radioterapiju $60 \mathrm{~Gy}$ po 2 Gy/frakcija dnevno tokom 6 tjedana s istodobnim TMZ-om $75 \mathrm{mg} / \mathrm{m} 2$, nakon čega je slijedilo šest ciklusa adjuvantnog TMZ-a 150-200 mg / m2 (dan 15) svaka 4 tjedna. Određene su Kaplan-Meierove procjene ukupnog preživljavanja (OS). Njihova studija pokazuje korist TMZ-a za pGBM pacijente (4). U radu Friedman GK, et al. retrospektivno su pregledana 3 slučaja glioblastoma u djece. Pacijenti su podvrgnuti agresivnoj hirurškoj resekciji. Pacijenti su započeli liječenje konformalnom radioterapijom (60 Gy u 30 frakcija) i Temozolomidom (90 mg/m2 oralno dnevno - 42 d), 29 dana nakon hirurške resekcije. Nakon kemoradioterapije i 4 tjedna odmora, pacijenti su započeli dvanaest 28-dnevnih ciklusa terapije održavanja koja se sastojala od Temozolomida (200 mg/m2 oralno 1. do 5. dana). Ova retrospektivna serija slučajeva sugerira da je moguće liječiti glioblastom u dječjoj dobi agresivnom hirurškom resekcijom i adjuvantnim Temozolomidom i Bevacizumabom istodobno s konformalnom radioterapijom kao i nakon terapije (5).

\section{Zaključak}

Naše istraživanje pokazuje korist primjene konkomitantne kemoradioterapije TMZ -a za pGBM pacijente. Prikazani slučaj liječenja GBM-a potvrđuje da je radioterapija $s$ istodobnim i adjuvantnim TMZ-om terapija izbora za bolje ukupno preživljenje u ovoj skupini pacijenata sa maksimalno sigurnom hirurškom resekcijom. Osim toga, čini se da primjena radioterapijske tehnike volumetrijski modulirane lučne terapije izvedene uz primjenu savremenih IGRT metoda, ima značajan doprinos ukupnom preživljavanju pedijatrijskih pacijenata sa BGM-om, što u usporedbi sa naučno dokazanim medijanom preživljenja upućuje na dobar terapijski učinak. U odnosu na konvencionalne metode, postiže se daleko veća pošteda okolnog zdravog tkiva. Primjena snimaka magnetne rezonance doprinijela je preciznijem planiranju radioterapijskog liječenja, kao i postterapijskom praćenju učinka tretmana $i$ ishoda bolesti. Ovaj rezultat podupire daljnje istraživanje ovoga terapijskog režima. Također, ovaj se režim dobro podnosi i ishodi su vrlo obećavajući.

\section{Reference}

1. Kanti Das K, Kumar R, Department of Neurosurgery, Sanjay Gandhi Postgraduate Institute of Medical Sciences, Lucknow, UP, India. Pediatric Glioblastoma. In: Department of Neurosurgery, University Hospitals Leuven, Leuven, Belgium, De Vleeschouwer S, editors. Glioblastoma [Internet]. Codon Publications; 2017 [cited 2021 Apr 25]. p. 297-312. Doi: http://dx.doi.org/10.15586/codon.glioblas toma.2017.ch15

2. Vanan MI, Eisenstat DD. Management of high-grade gliomas in the pediatric patient: Past, present, and future. Neuro-Oncology Practice. 2014 Dec 1;1(4):145-57. doi:10.1093/nop/npu022

3. Jalali R, Rishi A, Goda JS, Sridhar E, Gurav M, Sharma P, et al. Clinical outcome and molecular characterization of pediatric glioblastoma treated with postoperative radiotherapy with concurrent and adjuvant temozolomide: a single institutional study of 66 children. Neuro-Oncology Practice. 2016 Mar 1;3(1):39-47. doi:10.1093/nop/npv024

4. Gandhi A, Joshi N, Kumar A, Puri T, Haresh K, Gupta S, et al. Outcomes of pediatric glioblastoma treated with adjuvant chemoradiation with temozolomide and correlation with prognostic factors. Indian J Med Paediatr Oncol. 2015;36(2):99. Doi:10.4103/0971-5851.158838

5. Friedman GK, Spiller SE, Harrison DK, Fiveash JB, Reddy AT. Treatment of Children With Glioblastoma With Conformal Radiation, Temozolomide, and Bevacizumab as Adjuncts to Surgical Resection. Journal of Pediatric Hematology/Oncology. 2013 Apr;35(3):e123-6. Doi: 10.1097/MPH.0b013e318282cd7f · Source: PubMed 